\title{
What Is Research Misconducts? Publication Ethics Is as Important as Research Integrity
}

\author{
Chang-Sub Uhm*
}

Department of Anatomy, Korea University College of Medicine, Seoul 02841, Korea

*Correspondence to:

Uhm CS,

Tel: +82-2-2286-1150

Fax: +82-2-929-5696

E-mail: uhmcs@korea.ac.kr

Received June 26, 2016

Revised June 27, 2016

Accepted June 27, 2016

\begin{abstract}
Research ethics are mainly of two fields; research integrity and publication ethics. Research misconducts can occur at both areas. Examples of the research integrity violations are falsification, fabrication, and plagiarism; and those of the publication ethics violations are duplicate publication including self-plagiarism, and improper authorship. In this paper, concepts of research misconducts defined in Research Misconduct-related Rules of The Korean Society of Microscopy are explained and discussed.
\end{abstract}

Key Words: Research integrity, Research misconduct, Duplicate publication

\section{MOTIVATIONS TO PUBLISH}

Why do the researchers publish? In other words, what are the motivations to publish? Well, it may be different from each individual. First thing that comes up for me is to show colleagues what I have done, maybe to boast myself in part and to receive comments and advises on my future researches. The scientific study dealing with the motivation to publish is very rare. Bryan Coles' analysis on the motivation for publication can be found in the Royal Society's British Library R\&D Report 6123 (Royal Society \& BLAPLSP, 1993). Unfortunately, the original paper is not easily accessible, the important results cited can be found in several proceedings for the librarians and lecture notes for writing papers (Hughes, 2006). Other than the simple reason to boast oneself I mentioned at the beginning, other desires include to maximize the dissemination (54\%), to help career development (20\%), to improve funding (13\%), to help ego $(9 \%)$, and protect a patent $(4 \%)$, and others.

Whatever is the motivation to publish, the actual situation in the scientific field is very tough. The pressure to publish is increasing in recent years. Competitions among peers are tremendous. The number of papers and impact factor of the journal in which a paper is published, became the most important factor in the evaluation of the researcher's ability.
Promotions, funding and sharing of the funds, number of graduate students, and even waiving mandatory lecture hours are all based basically on what has been published! In addition, the recent introduction of commercialization concept into the scientific societies distracts scientists to pay attention to get the patent, to start-up a company from enjoying the research only.

\section{SOME HISTORIES}

In the United States, "research misconduct first attracted public's concern in the early 1980 's, when one researcher republished dozens of other scientists' papers under his name" (Steneck, 2007). The most notorious research misconduct scandal in Korea; so-called 'Hwang WooSuk scandal' happened in 2005. It was a very sad moment that one of the pioneering scientists in the cloning science became infamous for violating research ethics. His violation covers embezzlement, violations of bioethics law of Korea. Hwang's case showed many ethical violations; fabrication and falsification of data, unqualified authorship, unlawful Institutional Review Board review, and abuse of students' right and failing rights of human subjects. Many people also blamed Korean government. Herbert Gottweis of the University of Vienna and Robert Triendl of the RIKEN

(a) This is an open-access article distributed under the terms of the Creative Commons Attribution Non-Commercial License (http://creativecommons.org/licenses/by-nc/4.0) which permits unrestricted noncommercial use, distribution, and reproduction in any medium, provided the original work is properly cited.

Copyrights @ 2016 by Korean Society of Microscopy 
Research Center wrote a commentary in Nature Biotechnolgy, where they claimed that "poor national mechanisms for accountability, competition, transparency and ethical oversight allowed Hwang Woo-Suk's descent into ethical, and ultimately scientific, misconduct" (Gottweis \& Triendl, 2006). Even though there were research misconducts attracted public concerns, it is only after Dr. Hwang's scandal, the Ministry of Education of Korea enacted "Guidelines to ensure research ethics" to ensure the research integrity in Korean scientific societies. The guideline was first enacted in 2007 , and has been revised several times to the final version of 2014 . Many schools and academic societies also enacted rules or regulations to ensure the research integrity, to prevent research misconducts. Those guidelines, rules, and regulations provide how to cope with the research ethics violations. The Korean Society of Microscopy (KSM) also made "Research Misconductrelated Rules (RMRR)" effective since May 24, 2012. The rule can be found at the Society's homepage (The Korean Society of Microscopy, 2012; http://ksem.com/page_mORE17).

If you find any suspicions on research misconduct related to the papers whether published or submitted, you are subject to report to the Editorial Board of the Applied Microscopy, the official journal published by KSM.

\section{RESEARCH MISCONDUCTS}

"Research misconducts can be divided into 2 major categories; research integrity violations and publication ethics violations" (Kim, 2010). Main research integrity violations include fabrication, falsification, and plagiarism. Publications ethics violations include duplicate publication and/or selfplagiarism, and inappropriate authorship. Many people think the research integrity violations are equal to criminal acts due to the endeavors of the government, universities, research institutions, and academic societies. Publications ethics violations, on the other hand, are not treated as important as research integrity violations. For example, in the past, it was kind of a custom to put the supervisor's name at the senior author position to express respect and gratitude, whether he or she contributed to that specific research to earn the authorship or not. Even in recent years, some young scientists just followed the custom naively, put themselves to a positon blamed by violating publication ethics.

The chapter II of RMRR of KSM defines major misconducts. Article 4 defines falsification as the act to make untruthful data or experimental results which are not present; the fabrication is to distort the research results either by modifying the materials and experimental methods, or by changing the obtained data as he pleased. Researchers suspected of doing falsification and/or fabrication are often asked to reproduce the results openly.

Article 5 defines plagiarism as using intentionally other's published scientific ideas, opinions, expressions, and scientific results without appropriate citation; that is revealing the sources. Publications include scientific journals, abstracts and proceedings of the meetings, research reports, thesis and dissertations, books, magazines, and even the internet postings. If anyone uses a part of his or her own published paper without citation, it is also regarded as plagiarism. There is no golden rule what the 'appropriate citation' is. Different academic societies have different views. Recent trend is to mark quotation marks when more than a sentence is used from the published sources.

Article 6 prohibits the submission which has been submitted or is under consideration to be submitted to the other journals at the same time. And article 7 bans the duplicate publication of the same paper. Because duplicate submission often leads to the duplicate publication, it is advised not to resubmit any papers submitted before unless you are certain that it has not been accepted. Because many schools have a rule to compel publishing papers before submitting the graduation thesis or dissertation, some students make mistakes to resubmit the paper to the second journal before confirming the rejection from the first journal.

There are few allowed exceptions for duplicate publications. Papers published in journals not indexed to any journal indexing systems or presented at the scientific meetings can be published with revisions with an appropriate permission from both parties. Research report needs to get permission from the grant-providing organizations. In this case, the author needs to pay attention whether any parts of the paper considered for publication include the classified information, even though work has been done by the authors. Another example is to publish a thesis paper to the regular journals or vice versa. A graduation thesis or degree dissertation is often published in the form of bound book, distributed to the limited scientists, and kept in the library. Therefore many researchers want to publish the thesis paper in regular scientific journals to disseminate the results of the research. Also, in recent years, many schools require mandatory publication of the experimental results before graduation; therefore, in some cases, thesis papers are written based on the already published works. Both cases are allowed in the scientific community only such fact is recorded properly. That is whichever is later in publication sequence, you should mention either the article is based on the thesis, or the thesis is based on the already published papers. In this case, exceptionally, it is not necessary to get permission from the publisher or the school. Other than the thesis paper, you need to get permission from both publishers for the duplicate publication, and the fact should be recorded as an acknowledgment in the second paper in addition to the proper citation. 


\section{PUBLICATION ETHICS VIOLATIONS: DUPLICATE PUBLICATION}

As I already pointed out, the research integrity violations have been decreased due to the combined effort of the scientific societies and education. Instead, the concerns are moving toward the publication ethics violations, especially the duplicate publication or self-plagiarism.

In duplicate publication, part or whole of the paper is same to the previously published paper of the author. The partial duplicate is sometimes called as self-plagiarism, or reusing the text. Because nobody can steal something of their own, the plagiarism of their own work does not conceptually valid. However, because in most cases, copyright is transferred to the publisher, reusing part or whole of the previously published paper may infringe a copyright. In all these cases, the same contents are reused, they can be categorized into a single concept; duplicate publication.

The first systematic study on the duplicate publication in Korean indexed journal was reported in 2008 (Kim et al., 2008). They evaluated published papers indexed in KoreaMed data from January to December 2004. The duplicate publication was $5.93 \%$. Since that time, Kim (2015) monitored for duplicate publication every year from 2005 to 2008 . The results were $5.99 \%, 7.17 \%, 4.54 \%, 2.78 \%$, and $1.19 \%$ respectively. The decreasing trend in Korea is very apparent at least in the medical journals.

The duplicate publication in journals indexed in Medline varies from $0.2 \%$ to $28 \%$ mostly less than $1 \%$ depending on the researchers (Bailey, 2002; Blancett et al., 1995; Errami \& Garner, 2008; Errami et al., 2008; Rosenthal et al., 2003; Sorokina et al., 2006). Except for 2 papers reporting 8.5\% (Rosenthal et al., 2003) and 28\% (Blancett et al., 1995) of duplicate publication, most of the researchers report less than
$1 \%$ of duplicate publication, which are relatively lower than Kim's reports (Kim, 2015; Kim et al., 2008). This discrepancy may be caused by the different standards deciding the duplicate.

Interestingly "the duplicate papers are published at the same year or one year apart suggesting both papers were submitted at the simultaneously. Also duplicate papers are generally published in journals with impact factors below the average of their field and obtain lower citations" (Lariviere \& Gingras, 2010). This means that duplicate publication is an act to increase the possible dissemination of the work to the specialists of the same field. Recently second papers tend to be published in journals with higher impact factor. This may be due to the evaluation system that gives benefit to the papers in the major journals. It is noted at this point that, even in cases when the duplicate publications are allowed as in thesis to journal paper, research report to journal paper, and conference abstract to regular papers; taking benefits by using both papers in duplicate are not allowed. That is if you use both papers for the promotion or to get research funds, it is regarded as serious ethics violation.

\section{SUMMARY}

To wrap up the discussion, it is advised to remember however trivial the misconduct is, it can ruin the career as a scientist. Excellent scientists not only follow the research designs precisely as planned but also keep them from violating the ethics principles.

\section{CONFLICT OF INTEREST}

No potential conflict of interest relevant to this article was reported.

\section{REFERENCES}

Bailey B J (2002) Duplicate publication in the field of otolaryngology-head and neck surgery. Otolaryngol. Head Neck Surg. 126, 211-216.

Blancett S S, Flanagin A, and Young R K (1995) Duplicate publication in the nursing literature. Image J. Nurs. Sch. 27, 51-56.

Errami M and Garner H (2008) A tale of two citations. Nature 451, 397399.

Errami M, Hicks J M, Fisher W, Trusty D, Wren J D, Long T C, and Garner H R (2008) Deja vu-a study of duplicate citations in Medline. Bioinformatics 24, 243-249.

Gottweis H and Triendl R (2006) South Korean policy failure and the Hwang debacle. Nature Biotech. 24, 141-143.

Hughes C A (2006) A view from an academic librarian. In: Charleston Conference Proceedings 2004, eds. Bazirjian R, Speck V H, and Bernhardt B R, pp. 113-122, (Libraries Unlimited, Santa Barbara).
Kim H S (2010) Interdisciplinary relation to establish research ethics. In: The Theme and Prospect of Research Ethics. The 1st 2010 Research Ethics Forum, pp. 13-30, (The Korean Association of Academic Societies, Seoul).

Kim S Y (2015) The status of duplicate publication in medical fields. In: Research Ethics: Practical issues and policies II. The 2nd 2015 Research Ethics Forum, pp. 7-36, (The Korean Association of Academic Societies, Seoul).

Kim S Y, Hahm C K, Bae C W, and Cho H M (2008) Duplicate publications in Korean Medical Journals Indexed in KoreaMed. J. Korean Med. Sci. 23, 131-133.

Lariviere V and Gingras $Y(2010)$ On the prevalence and scientific impact of duplicate publications in different scientific fields (1980-2007). J. Documentation 66, 179-190. 
Rosenthal E L, Masdon J L, Buckman C, and Hawn M (2003) Duplicate publications in the otolaryngology literature. Laryngoscope 113, 772 774.

Royal Society and The British Library and Association of Professional and Learned Society Publishers (BLAPLSP) (1993) The Scientific, Technical and Medical Information System in the UK, British Library R\&D Report 6123, (Royal Society, London).

Sorokina D, Gehrke J, Warner S, and Ginsparg P (2006) Plagiarism detection in arXiv. In: Proceedings of the $6^{\text {th }}$ IEEE International Conference on Data Mining (ICDM'06), pp. 1070-1075, (IEEE, Hong Kong).

Steneck N H (2007) ORI (The Office of Research Integrity) Introduction to the Responsible Conduct of Research. Revised ed. (Department of Health \& Human Services, Bethesda).

The Korean Society of Microscopy (2012) Research Misconduct-related Rules [Internet]. Available form: http://ksem.com/page_mORE17. 